\title{
Risk Factors for Chronic Kidney Disease among American Indians and Alaska Natives - Findings from the Kidney Early Evaluation Program
}

\author{
Stacey E. Jolly ${ }^{a}$ Suying $\mathrm{Li}^{\mathrm{b}}$ Shu-Cheng Chen ${ }^{\mathrm{b}}$ Andrew S. Narva ${ }^{\mathrm{c}}$ \\ Claudine T. Jurkovitz ${ }^{d}$ Keith C. Norris ${ }^{e}$ Michael G. Shlipak ${ }^{a, f}$ \\ ${ }^{a}$ General Internal Medicine Division, University of California San Francisco, San Francisco, Calif., \\ ${ }^{b}$ Chronic Disease Research Group, Minneapolis Medical Research Foundation, Minneapolis, Minn., \\ 'National Institute of Diabetes and Digestive and Kidney Diseases, Bethesda, Md., dCenter for Outcomes Research, \\ Christiana Care Health System, Newark, Del., e Department of Internal Medicine, Charles R. Drew University, \\ Los Angeles, Calif., and ${ }^{\mathrm{f} S a n}$ Francisco VA Medical Center, San Francisco, Calif., USA
}

\section{Key Words}

Chronic kidney disease • Risk factors • American Indians •

Alaska Natives

\begin{abstract}
Background: American Indians and Alaska Natives (AIAN) have a high incidence of end-stage renal disease. Less is known about chronic kidney disease (CKD) among AIAN and whether risk factors differ for low estimated glomerular filtration rate (eGFR) versus albuminuria with a normal eGFR. Methods: Cross-sectional study examining the associations of age, sex, smoking, obesity, diabetes, hypertension, family history, and geographic region with CKD among a screened population of AIAN participants in the Kidney Early Evaluation Program from 2000 to 2006. CKD was defined by the presence of either a low eGFR, $<60 \mathrm{ml} / \mathrm{min} / 1.73 \mathrm{~m}^{2}$, or albuminuria, a urine albumin/creatinine ratio $\geq 30 \mathrm{mg} / \mathrm{g}$. Results: The prevalence of any CKD was $29 \%$, of low eGFR was $17 \%$, and of albuminuria with a normal eGFR was $12 \%$. Older age was the strongest predictor of low eGFR (61+ years OR 8.42, 95\% Cl 5.92-11.98), followed by hypertension (OR 2.38, 95\% Cl 1.74-3.26). In contrast, diabetes (OR 2.04, 95\% Cl 1.57-2.64) and hypertension (OR 2.63, 95\% Cl 1.93-3.59) were the only predictors of albuminuria among persons with a normal
\end{abstract}

\section{KARGER}

Fax +41613061234 E-Mail karger@karger.ch www.karger.com
(C) 2008 S. Karger AG, Basel

0250-8095/09/0295-0440\$26.00/0

Accessible online at:

www.karger.com/ajn
eGFR. Conclusion: The burden of CKD was high among this screened population of AIAN, and different risk factor patterns were associated with low eGFR and albuminuria. Innovative programs and longitudinal research are needed to address CKD among AIAN.

Copyright $\odot 2008$ S. Karger AG, Basel

\section{Introduction}

American Indians and Alaska Natives (AIAN) have double the incidence of end-stage renal disease (ESRD) compared to whites [1]. Nearly three-quarters of all incident ESRD cases among AIAN have been attributable to diabetes [1]. A high prevalence of albuminuria among AIAN with diabetes (30-50\%) and without diabetes $(5 \%-15 \%)$ has been described [2-6].

Less is known about chronic kidney disease (CKD), as defined by Kidney Disease Outcomes Quality Initiative guidelines [7] among AIAN, and specifically whether risk factors may differ for a low estimated glomerular filtration rate (eGFR) versus albuminuria with a normal eGFR. Understanding the distribution of CKD risk factors among AIAN and their contribution to the risk of CKD is important because certain candidate risk factors, 
such as diabetes, are increasing among the AIAN population $[8,9]$. Knowledge of CKD and its risk factors may lead to improved screening, prevention and early intervention in this high-risk group.

We utilized data from the Kidney Early Evaluation Program (KEEP) of the National Kidney Foundation (NKF) to describe the burden of CKD among a screened population of AIAN. In addition, we estimated the strength of associations of candidate risk factors for CKD between having a low eGFR $\left(<60 \mathrm{ml} / \mathrm{min} / 1.73 \mathrm{~m}^{2}\right)$ and albuminuria $(>30 \mathrm{mg} / \mathrm{g})$ with a normal eGFR.

\section{Methods}

\section{Study Population}

The KEEP study is a free, community-based, voluntary screening program designed to identify individuals at increased risk for kidney disease and to encourage them to seek follow-up care [10]. KEEP screening sites are conducted throughout the USA through each state's local NKF affiliate site [11]. The screening program which has been previously described takes place in both urban and rural locations [10]. The geographic region included is 49 states, except Alaska, and the District of Columbia. Eligible participants are men or women at least 18 years of age with either a personal diagnosis of diabetes mellitus or hypertension, or with a family history of diabetes, hypertension, or CKD. Participants who had received transplants or were on regular dialysis treatment were excluded from this analysis.

\section{Screening Protocol}

Screening data were collected on participant demographic characteristics, personal and family medical history, and health behaviors [10]. One-time systolic and diastolic blood pressure measurements were obtained, and blood and urine specimens were collected and processed for determination of serum creatinine and urine albumin levels [10].

\section{Predictor Variables}

Potential CKD risk factors examined were age, sex, smoking, obesity, diabetes, hypertension, family history of CKD, family history of diabetes, and geographic region. Age was determined by self-reported date of birth at the time of screening and categorized into three groups: $18-45,46-60$, and $\geq 61$ years of age. Smoking status was self-reported and categorized as current, former, or never. Diabetes was diagnosed by either participant selfreport, fasting glucose values $\geq 126 \mathrm{mg} / \mathrm{dl}$, or non-fasting glucose values $\geq 140 \mathrm{mg} / \mathrm{dl}$. Hypertension was diagnosed by either participant self-report or systolic blood pressure $\geq 140 \mathrm{~mm} \mathrm{Hg}$ or diastolic blood pressure $\geq 90 \mathrm{~mm} \mathrm{Hg}$ in the absence of diabetes or CKD; systolic blood pressure $\geq 130 \mathrm{~mm} \mathrm{Hg}$ or diastolic blood pressure $\geq 80 \mathrm{~mm} \mathrm{Hg}$ were the cut points if diabetes or CKD was present. Obesity was defined as a body mass index of $\geq 30$. Family history of diabetes and family history of kidney disease were determined by participant self-report of having a first-degree relative with diabetes or CKD, respectively. The USA was categorized into four geographic screening regions that corresponded to the nine US Census divisions which correlated with Indian Health Service geographic regional areas in order to examine potential regional differences for CKD and risk factors. The Northeast region includes the following states (CT, ME, MA, NH, RI, VT, NJ, NY, PA), the Midwest includes (IL, IN, MI, OH, WI, IA, KS, MN, $\mathrm{MO}, \mathrm{NE}, \mathrm{ND}, \mathrm{SD}$ ), the South includes (DE, DC, FL, GA, MD, NC, SC, VA, WV, AL, KY, MS, TN, AR, LA, OK, TX), and the West includes (AZ, CO, ID, MT, NV, NM, UT, WY, AK, CA, HI, OR, WA).

\section{Outcome Variables}

Serum creatinine values for KEEP study participants were calibrated against values measured at Cleveland Clinic Research Laboratory using the Roche enzymatic assay. Subsequently, eGFR using the original (raw) serum creatinine value was re-calculated using the re-expressed Modification of Diet in Renal Disease Study equation with the newly calibrated serum creatinine values $[12,13]$. Spot urine specimens were collected and tested for microalbuminuria with the Micral assay (Roche Pharmaceuticals, Indianapolis, Ind.) until September 2001, and then with a Clinitek assay (Bayer Diagnostics, Tarrytown, N.Y.) [10].

Presence of CKD was defined by a low eGFR or albuminuria based upon the Kidney Disease Outcomes Quality Initiative guidelines [7]. For this analysis, eGFR was dichotomized into a low eGFR $\left(<60 \mathrm{ml} / \mathrm{min} / 1.73 \mathrm{~m}^{2}\right)$ or a normal eGFR $(\geq 60 \mathrm{ml} /$ $\min / 1.73 \mathrm{~m}^{2}$ ) and albuminuria was defined as an abnormal urine albumin to creatinine ratio of $\geq 30 \mathrm{mg} / \mathrm{g}$. We examined three outcome variables: (a) presence of CKD and (b) low eGFR in the overall AIAN KEEP study population, and (c) albuminuria in the group of AIAN NKEEP study participants with a normal eGFR.

\section{Statistical Analysis}

We tabulated the proportion of AIAN KEEP study participants who had screening data available to calculate eGFR from the entire KEEP screened cohort who self-identified as AIAN. We then tabulated the proportion of AIAN participants who had any criteria for CKD, those with a low eGFR, and those with albuminuria and a normal eGFR. We then compared demographic characteristics and risk factor prevalence among AIAN participants without any CKD, with a low eGFR, and with albuminuria and a normal eGFR using $\chi^{2}$ analyses. For AIAN KEEP study participants with complete data for the potential risk factors, we calculated CKD prevalence within subgroups based upon age, sex, smoking status, presence of obesity, diabetes mellitus, hypertension, and geographic regions.

We conducted multivariate logistic regression analyses to determine which risk factors, or covariates, were independently associated with each of the three outcomes: (a) combined CKD outcome, (b) low eGFR, and (c) albuminuria among persons with normal eGFR. All potential risk factors, determined a priori, were included in the multivariable analyses. We also assessed for potential interactions between diabetes and hypertension with geographic region for our three CKD outcomes using the Wald test of heterogeneity. Prior cohort studies found regional differences in the prevalence of albuminuria among those with diabetes or hypertension [5].

Statistical analyses were performed with the SAS Statistical Package (Release 9.1; SAS Institute Inc., Cary, N.C., USA). 
Table 1. Comparison of risk factors among the AIAN KEEP study participants by CKD status

\begin{tabular}{|c|c|c|c|c|}
\hline Risk factor & $\begin{array}{l}\text { CKD absent } \\
(n=2,146)\end{array}$ & $\begin{array}{l}\text { Low eGFR }{ }^{1} \\
(\mathrm{n}=526)\end{array}$ & $\begin{array}{l}\text { Albuminuria with } \\
\text { normal eGFR } \\
(\mathrm{n}=365)\end{array}$ & $\mathrm{p}$ value \\
\hline \multicolumn{4}{|l|}{ Age, years } & $<0.0001$ \\
\hline $18-45$ & $978(46)$ & $50(10)$ & $142(39)$ & \\
\hline $46-60$ & $691(32)$ & $147(28)$ & $109(30)$ & \\
\hline$\geq 61$ & $477(22)$ & $329(62)$ & $114(31)$ & \\
\hline Male sex & $541(25)$ & $125(24)$ & $121(33)$ & 0.0028 \\
\hline Diabetes & $750(35)$ & $294(56)$ & $209(57)$ & $<0.0001$ \\
\hline Hypertension & $1,207(56)$ & $450(86)$ & $291(80)$ & $<0.0001$ \\
\hline Obesity $^{3}$ & $1,183(56)$ & $277(54)$ & $209(59)$ & 0.2869 \\
\hline Current or former smoker ${ }^{3}$ & $1,100(54)$ & $288(58)$ & $191(53)$ & 0.1593 \\
\hline Family history of diabetes ${ }^{3}$ & $1,685(80)$ & $366(73)$ & $278(79)$ & 0.0011 \\
\hline Family history of kidney disease ${ }^{3}$ & $524(25)$ & $128(25)$ & $93(26)$ & 0.9087 \\
\hline \multicolumn{4}{|l|}{ Region } & $<0.0001$ \\
\hline Northeast & $161(8)$ & $80(15)$ & $28(8)$ & \\
\hline Midwest & 402 (19) & $114(22)$ & $54(15)$ & \\
\hline South & $758(35)$ & $238(45)$ & $121(33)$ & \\
\hline West & $825(38)$ & $94(18)$ & $162(44)$ & \\
\hline \multicolumn{5}{|c|}{$\begin{array}{l}\text { Percentage values are shown in parentheses. } \\
{ }^{1} \text { Low eGFR defined as }<60 \mathrm{ml} / \mathrm{min} / 1.73 \mathrm{~m}^{2} \text {. } \\
{ }^{2} \text { Albuminuria defined as a urinary albumin to creatinine ratio } \geq 30 \mathrm{mg} / \mathrm{g} \text {. } \\
{ }^{3} \text { Excluding missing values. }\end{array}$} \\
\hline
\end{tabular}

\section{Results}

A total of 3,558 self-identified AIAN underwent screening through KEEP from August 1, 2000 to December 31, 2006. Data for determining eGFR were available for 3,037 (85\%) of the total screened AIAN participants and constituted our AIAN KEEP study population. Data for determining albuminuria among the AIAN study population were available for 2,966 (98\%) of those participants. The AIAN KEEP study population represents $4.9 \%$ of the entire KEEP cohort $(n=61,660)$ for which CKD status could be determined for the study period.

AIAN participants without creatinine measures $(\mathrm{n}=$ 521) had similar distribution of age, sex, prevalence of diabetes, hypertension, family history of diabetes, and family history of kidney disease compared with the included $(\mathrm{n}=3,037)$ AIAN participants. Except, smoking ( 67 vs. $55 \%, \mathrm{p}<0.001$ ) and obesity (61 vs. $56 \%$, p $=0.04$ ) were higher among the excluded participants.

Among the 3,037 AIAN-screened participants included, the average age was $51( \pm 18)$ years, $787(26 \%)$ were male, 1,669 (56\%) were obese, 1,253 (41\%) had diabetes, and $1,948(64 \%)$ had hypertension. One-quarter $(\mathrm{n}=745)$ reported a family history of kidney disease and 2,329
(79\%) reported a family history of diabetes. Out of the AIAN KEEP study population ( $\mathrm{n}=3,037), 891(29 \%)$ had CKD, 526 (17\%) had a low eGFR, and 365 (12\%) had albuminuria and a normal eGFR. AIAN participants with low eGFR were older compared to those without CKD or albuminuria with a normal eGFR (table 1). Both groups, those with low eGFR and albuminuria with a normal eGFR, had more diabetes and hypertension than those without CKD (table 1). There were no differences in the prevalence of obesity, smoking, and family history of kidney disease (table 1).

By region, the West had the most participants at 1,117 (55\%), followed by the South at 1,081 (35\%), then the Midwest at 570 (19\%), and lastly the Northeast at 269 (9\%). However, the percentage of CKD, defined as a low eGFR or albuminuria with a normal eGFR, among participants by region was highest was among those screened in the Northeast with $40 \%(\mathrm{n}=108)$, followed by the West with $32 \%(\mathrm{n}=359)$, the Midwest with 29\% ( $\mathrm{n}=168)$, and the South with $24 \%(n=256)$.

Approximately $36 \%$ of the AIAN over age 61 had a low eGFR, compared with only $4 \%$ of the AIAN age $18-45$ in an unadjusted analysis (fig. 1). We see a pattern of increasing prevalence of albuminuria with age, among par- 
Fig. 1. Prevalence of low eGFR among American Indian and Alaska Native Kidney Early Evaluation Program study participants $(\mathrm{n}=3,037)$, overall and by risk factor status.

Fig. 2. Prevalence of albuminuria among American Indian and Alaska Native Kidney Early Evaluation Program study participants with normal eGFR $(n=2,511)$, overall and by risk factor status.
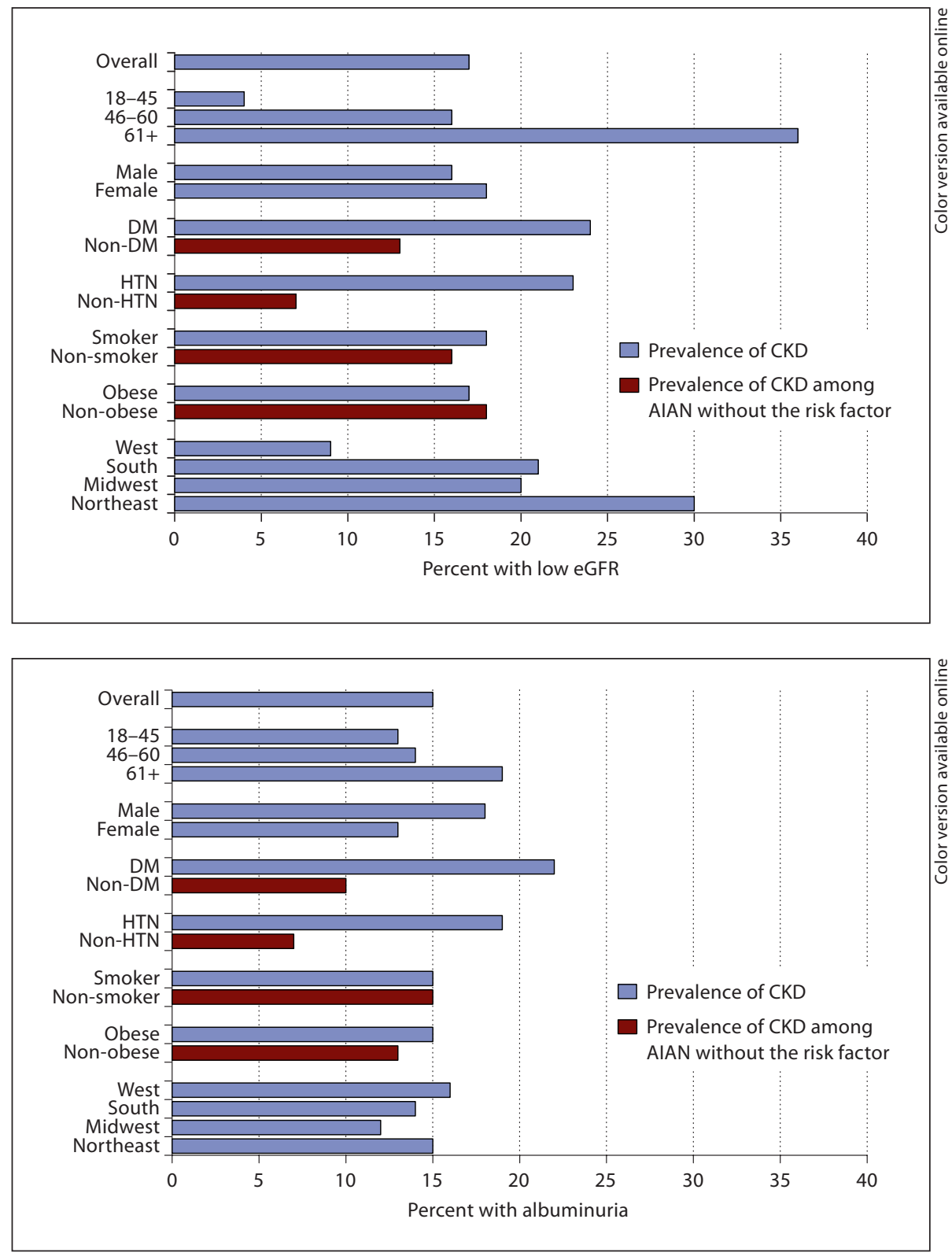

ticipants with a normal eGFR, or eGFR $\geq 60 \mathrm{ml} / \mathrm{min} /$ $1.73 \mathrm{~m}^{2}$ as well. Approximately $20 \%$ of AIAN over age 61 had albuminuria compared with $13 \%$ of AIAN age $18-45$ in an unadjusted analysis (fig. 2). Nearly 24\% of AIAN with either diabetes or hypertension had a low eGFR (fig. 1), and among those with a normal eGFR, approximately $20 \%$ of AIAN with either diabetes or hypertension had albuminuria (fig. 2).

Complete data for risk factors of interest were available for 2,725 (90\%) of our AIAN KEEP study population; in our fully adjusted models, age was most strongly associ- ated with a low eGFR, followed by hypertension, and male sex (table 2). Diabetes was not independently associated with a low eGFR (table 2). Complete data for risk factors of interest were available for 2,271 (90\%) of the AIAN KEEP study participants with a normal eGFR. Among these participants, hypertension and diabetes were strongly associated with albuminuria, but not age or male sex in our fully adjusted models (table 2).

We tested six potential interactions of geographic region and both diabetes and hypertension for predicting (a) the presence of CKD, (b) low eGFR, and (c) albumin-

Am J Nephrol 2009;29:440-446 
Table 2. Multivariate ${ }^{1}$ associations of risk factors among AIAN for low eGFR and albuminuria

\begin{tabular}{|c|c|c|}
\hline Risk factors & $\begin{array}{l}\text { Low eGFR }{ }^{2} \\
(\mathrm{n}=2,725) \\
\text { adjusted odds } \\
\text { ratio }(95 \% \mathrm{CI})\end{array}$ & $\begin{array}{l}\text { Albuminuria }^{3,4} \\
(\mathrm{n}=2,271) \\
\text { adjusted odds } \\
\text { ratio (95\% CI) }\end{array}$ \\
\hline \multicolumn{3}{|l|}{ Age (years) } \\
\hline $18-45$ & 1.00 & 1.00 \\
\hline $46-60$ & $3.01(2.09-4.32)$ & $0.78(0.58-1.05)$ \\
\hline$\geq 61$ & $8.42(5.92-11.98)$ & $1.01(0.73-1.38)$ \\
\hline Male & $0.65(0.49-0.85)$ & $1.28(0.98-1.67)$ \\
\hline Diabetes & $1.19(0.94-1.51)$ & $2.04(1.57-2.64)$ \\
\hline Hypertension & $2.38(1.74-3.26)$ & $2.63(1.93-3.59)$ \\
\hline Obesity & $0.94(0.74-1.18)$ & $0.93(0.72-1.20)$ \\
\hline Current or former smoker & $1.17(0.92-1.49)$ & $1.06(0.81-1.37)$ \\
\hline Family history of diabetes & $0.68(0.52-0.88)$ & $0.99(0.73-1.35)$ \\
\hline \multicolumn{3}{|c|}{ Family history of } \\
\hline kidney disease & $1.12(0.87-1.46)$ & $1.02(0.77-1.35)$ \\
\hline \multicolumn{3}{|l|}{ Region } \\
\hline West & 1.00 & 1.00 \\
\hline Northeast & $4.76(3.16-7.17)$ & $1.08(0.67-1.73)$ \\
\hline Midwest & $2.06(1.44-2.94)$ & $0.65(0.45-0.94)$ \\
\hline South & $2.09(1.55-2.82)$ & $0.72(0.54-0.96)$ \\
\hline
\end{tabular}

${ }^{1}$ Fully adjusted model in which all variables of interest were adjusted simultaneously.

2 eGFR $<60 \mathrm{ml} / \mathrm{min} / 1.73 \mathrm{~m}^{2}$.

${ }^{3}$ Albumin to creatinine ratio $\geq 30 \mathrm{mg} / \mathrm{g}$ with an eGFR $\geq 60 \mathrm{ml} /$ $\min / 1.73 \mathrm{~m}^{2}$.

${ }^{4}$ Excludes eGFR $<60$.

uria with normal eGFR. Only for the outcome of presence of CKD was there a significant interaction for the association of hypertension and geographic region. Among participants with hypertension, the associations of Northeast and Midwest region with CKD were 3.54 and 1.89 odds ratios, respectively; whereas among those without hypertension, the associations of those regions were less at 1.68 and 0.81 odds ratios, respectively ( $\mathrm{p}$ for interaction $=0.01$.

\section{Discussion}

Nearly one-third of the AIAN participants screened with KEEP had CKD, 17\% had a reduced eGFR and $12 \%$ had albuminuria with a normal eGFR. On average, AIAN with CKD were older and more likely to have diabetes and hypertension. The relative associations of these risk factors with a low eGFR and albuminuria with a normal eGFR were notably different. Age was the strongest pre- dictor of low eGFR, followed by hypertension and smoking, but not diabetes. In contrast, diabetes and hypertension were the only predictors of albuminuria with a normal eGFR.

Among those with diabetes, we found a prevalence of albuminuria of nearly $22 \%$, which is similar to findings from studies conducted among specific tribes or specific geographic regions $[4,5,14,15]$. For example, in the Zuni Kidney Project, $36 \%$ of the men and 32\% of the women with diabetes had albuminuria [16]. In the Strong Heart Study, a cohort examining cardiovascular risk factors among AIAN, the prevalence of albuminuria varied by region and ranged from $28 \%$ in the Southwest to $14 \%$ in the Dakotas [5]. We also observed an association of geographic region with CKD, with the West region having the lowest odds of low eGFR and higher odds of albuminuria with a normal eGFR as compared to the Midwest and South regions. This increased risk is likely due to the influence of diabetes which is known to be higher among AIAN living in the West region. Among AIAN with diabetes in the Strong Heart Study, higher blood pressure, lack of angiotension-converting enzyme inhibitor use, smoking, and use of diabetic medicines independently predicted the development of incident albuminuria [17]. In addition to diabetes, we highlight risk factors such as age, hypertension, and smoking. In contrast to the results of other studies [3, 18], we did not find that obesity was associated with albuminuria. The influence of obesity, which was present in over half the participants, may have been captured indirectly by its effects on hypertension and diabetes.

We observed differing risk factor patterns for low eGFR versus albuminuria, which suggest they may represent two distinct CKD phenotypes in this population and adds to the discussion of the clinical utility of the current staging system of CKD [19]. Unlike a low eGFR, albuminuria was not associated with the risk factors of age, sex, or smoking. A low eGFR was associated with hypertension, but not diabetes, while albuminuria was strongly associated with both. Among AIAN, albuminuria most likely characterizes persons who have diabetes or hypertension, and are at greatest risk for progression to ESRD $[1,20,21]$ and have elevated risk for cardiovascular disease [22-24]. Men had a lower independent risk of having a low eGFR in our KEEP study among AIAN. We cannot distinguish whether the difference observed is a real difference in underlying GFR, or a bias of the equation used to estimate GFR because of the correction factor that lowers eGFR in women. Nor do we know if the men in KEEP are more self-selected as 'healthy volun- 
teers' than women compared to the overall AIAN community. With increasing age, AIAN are likely to have a low eGFR. In our study among AIAN participants aged 61 or older, $37 \%$ had low eGFR. In comparison, from the National Health Nutrition and Examination Survey (NHANES), the prevalence of low eGFR was $15 \%$ for persons aged 60-69, and 35\% for those 70 and older [25]. AIAN with low eGFR but no albuminuria may be at greater risk for developing cardiovascular disease, heart failure and death than for developing ESRD [26].

Our study has several limitations. This is a screened population of AIAN who elected to participate in the KEEP study which specifically targets individuals at elevated risk for kidney disease. Even though CKD in the KEEP study cohort has been shown to be similar to the subgroup of participants with CKD in NHANES [27], our results specifically may overestimate the prevalence of CKD among all AIAN in the USA. The AIAN population comprises $1.5 \%$ of the total US population [28], whereas AIAN participants were $4.9 \%$ of the overall KEEP study population. We did not look at other forms of kidney disease such as IgA nephropathy glomerulonephritis, which is common among the Zuni tribe in the Southwest [29]. We are not able to accurately stratify our cohort by tribes. Our data are cross-sectional and therefore cannot account for changes in risk factors or outcome status over time. Some of our data are based on selfreport from questionnaires and therefore are subject to potential recall and ascertainment bias; however, prior work has shown ascertainment of disease status by selfreport to be valid [30]. We did not have complete data on all AIAN participants in the KEEP study. However, we showed that those with and without data to determine CKD status by eGFR were similar, and therefore unlikely to have affected the results seen. A single random sample of urine was collected to measure albumin and creatinine, rather than repeated measures as recommended for clinical practice [7]. A lack of statistical power may have limited our ability to detect significant interactions between geographical region and diabetes or hypertension in association with outcomes of low eGFR and albuminuria with a normal eGFR. We did not examine socioeconomic factors, such as lower income or lower level of education attainment, which have been shown to be associated with CKD among AIAN and other ethnic minority populations [3, 31, 32].

The prevalence of CKD among AIAN participants in KEEP was high and the independent risk factors for low eGFR were different than for albuminuria with a normal eGFR. Many of the CKD risk factors are potentially modifiable, yet are rising. Preventative and treatment interventions will be required to mitigate the burden of $\mathrm{CKD}$, and ultimately ESRD, among AIAN.

\section{Disclosure}

The authors have no relevant financial interest in the study. The views of this article do not represent those of the affiliated institutions where the authors work nor those of the National Institute of Diabetes and Digestive and Kidney Diseases (NIDDK).

\section{Acknowledgements}

Dr. Jolly was supported by Health Resources and Services Administration Faculty Development in Primary Care Grant D55HP05165 for this study. Dr. Shlipak's effort on this paper was supported by R01-DK066488, R01-AG027002, and the American Heart Association's Established Investigator Award.

\section{References}

1 United States Renal Data System: USRDS 2006 Annual Data Report. National Institute of Diabetes and Digestive and Kidney Diseases, National Institutes of Health, 2006.

$\checkmark 2$ Hirata-Dulas CA, Rith-Najarian SJ, McIntyre MC, Ross C, Dahl DC, Keane WF, Kasiske BL: Risk factors for nephropathy and cardiovascular disease in diabetic Northern Minnesota American Indians. Clin Nephrol 1996;46:92-98.

-3 Kasiske BL, Rith-Najarian S, Casper ML, Croft JB: American Indian heritage and risk factors for renal injury. Kidney Int 1998;54: $1305-1310$
-4 Nelson RG, Morgenstern H, Bennett PH: An epidemic of proteinuria in Pima Indians with type 2 diabetes mellitus. Kidney Int 1998;54:2081-2088.

5 Robbins DC, Knowler WC, Lee ET, Yeh J, Go OT, Welty T, Fabsitz R, Howard BV: Regional differences in albuminuria among American Indians: an epidemic of renal disease. Kidney Int 1996;49:557-563.

6 Sosenko JM, Hu D, Welty T, Howard BV, Lee E, Robbins DC: Albuminuria in recent-onset type 2 diabetes: the Strong Heart Study. Diabetes Care 2002;25:1078-1084.
7 National Kidney Foundation: Kidney Disease Outcomes Quality Initiative Guideline. Am J Kidney Dis 2002;39:S32-S36.

8 Diagnosed Diabetes among American Indians and Alaska Natives aged $<35$ years United States, 1994-2004. Morb Mortal Wkly Rep 2006;55:1201-1203.

-9 Acton KJ, Burrows NR, Moore K, Querec L, Geiss LS, Engelgau MM: Trends in diabetes prevalence among American Indian and Alaska Native children, adolescents, and young adults. Am J Public Health 2002;92: 1485-1490. 
$\checkmark 10$ Brown WW, Peters RM, Ohmit SE, Keane WF, Collins A, Chen SC, King K, Klag MJ, Molony DA, Flack JM: Early detection of kidney disease in community settings: The Kidney Early Evaluation Program (KEEP). Am J Kidney Dis 2003;42:22-35.

11 National Kidney Foundation: Kidney Early Evaluation Program (KEEP) 2006 Annual Data Report, vol 49, suppl 3, March 2007, S1S160.

$>12$ Levey AS, Coresh J, Greene T, Marsh J, Stevens LA, Kusek JW, Van Lente F: Expressing the modification of diet in renal disease study equation for estimating glomerular filtration rate with standardized serum creatinine values. Clin Chem 2007;53:766-772.

$>13$ Levey AS, Coresh J, Greene T, Stevens LA, Zhang YL, Hendriksen S, Kusek JW, Van Lente F: Using standardized serum creatinine values in the modification of diet in renal disease study equation for estimating glomerular filtration rate. Ann Intern Med 2006;145:247-254.

-14 Stidley CA, Shah VO, Narva AS, Dalton D, MacCluer JW, Bobelu A, Scavini M, Welty TK, Zager PG: A population-based, crosssectional survey of the Zuni Pueblo: a collaborative approach to an epidemic of kidney disease. Am J Kidney Dis 2002;39:358-368.

$\checkmark 15$ Megill DM, Hoy WE: Risk factors for renal disease in a native American community. Transplant Proc 1989;21:3902-3905.

-16 Stidley CA, Shah VO, Scavini M, Narva AS, Kessler D, Bobelu A, MacCluer JW, Welty TK, Zager PG: The Zuni Kidney Project: a collaborative approach to an epidemic of kidney disease. J Am Soc Nephrol 2003;14: S139-S143.

-17 Xu J, Lee ET, Devereux RB, Umans JG, Bella JN, Shara NM, Yeh J, Fabsitz RR, Howard BV: A longitudinal study of risk factors for incident albuminuria in diabetic American Indians: the Strong Heart Study. Am J Kidney Dis 2008;51:415-424.
18 Valencia ME, Weil EJ, Nelson RG, Esparza J, Schulz LO, Ravussin E, Bennett PH: Impact of lifestyle on prevalence of kidney disease in Pima Indians in Mexico and the United States. Kidney Int Suppl 2005:S141-S144.

19 Bauer C, Melamed ML, Hostetter TH: Staging of chronic kidney disease: time for a course correction. J Am Soc Nephrol 2008; 19:844-846

20 Pavkov ME, Bennett PH, Knowler WC, Krakoff J, Sievers ML, Nelson RG: Effect of youth-onset type 2 diabetes mellitus on incidence of end-stage renal disease and mortality in young and middle-aged Pima Indians. JAMA 2006;296:421-426.

21 Burrows NR, Narva AS, Geiss LS, Engelgau $\mathrm{MM}$, Acton KJ: End-stage renal disease due to diabetes among Southwestern American Indians, 1990-2001. Diabetes Care 2005;28: 1041-1044.

22 Dinneen SF, Gerstein HC: The association of microalbuminuria and mortality in non-insulin-dependent diabetes mellitus. A systematic overview of the literature. Arch Intern Med 1997;157:1413-1418.

23 Gerstein HC, Mann JF, Yi Q, Zinman B, Dinneen SF, Hoogwerf B, Halle JP, Young J, Rashkow A, Joyce C, Nawaz S, Yusuf S: Albuminuria and risk of cardiovascular events, death, and heart failure in diabetic and nondiabetic individuals. JAMA 2001;286:421426.

24 Jager A, Kostense PJ, Ruhe HG, Heine RJ, Nijpels G, Dekker JM, Bouter LM, Stehouwer CD: Microalbuminuria and peripheral arterial disease are independent predictors of cardiovascular and all-cause mortality, especially among hypertensive subjects: fiveyear follow-up of the Hoorn Study. Arterioscler Thromb Vasc Biol 1999;19:617-624.

25 Coresh J, Selvin E, Stevens LA, Manzi J, Kusek JW, Eggers P, Van Lente F, Levey AS: Prevalence of chronic kidney disease in the United States. JAMA 2007;298:2038-2047.

-26 Keith DS, Nichols GA, Gullion CM, Brown JB, Smith DH: Longitudinal follow-up and outcomes among a population with chronic kidney disease in a large managed care organization. Arch Intern Med 2004;164:659663.
27 Whaley-Connell AT, Sowers JR, Stevens LA, McFarlane SI, Shlipak MG, Norris KC, Chen SC, Qiu Y, Wang C, Li S, Vassalotti JA, Collins AJ: CKD in the United States: Kidney Early Evaluation Program (KEEP) and $\mathrm{Na}$ tional Health and Nutrition Examination Survey (NHANES) 1999-2004. Am J Kidney Dis 2008;51:S13-S20.

28 United States Census Bureau: The American Indian and Alaska Native populations, Census 2000 Brief, US Department of Commerce Economics and Statistics Administration, February 2002.

-29 Shah VO, Scavini M, Stidley CA, Tentori F, Welty TK, MacCluer JW, Narva AS, Bobelu A, Albert CP, Kessler DS, Harford AM, Wong CS, Harris AA, Paine S, Zager PG: Epidemic of diabetic and nondiabetic renal disease among the Zuni Indians: the Zuni Kidney Project. J Am Soc Nephrol 2003;14:13201329.

30 Okura Y, Urban LH, Mahoney DW, Jacobsen SJ, Rodeheffer RJ: Agreement between selfreport questionnaires and medical record data was substantial for diabetes, hypertension, myocardial infarction and stroke but not for heart failure. J Clin Epidemiol 2004; 57:1096-1103.

-31 Martins D, Tareen N, Zadshir A, Pan D, Vargas R, Nissenson A, Norris K: The association of poverty with the prevalence of albuminuria: data from the Third National Health and Nutrition Examination Survey (NHANES III). Am J Kidney Dis 2006;47: 965-971.

32 Nicholas SB, Tareen N, Zadshir A, Martins D, Pan D, Norris KC: Management of early chronic kidney disease in indigenous populations and ethnic minorities. Kidney Int Suppl 2005:S78-S81. 